\title{
Vardenafil versus Tamsulosin as a Medical Expulsive Therapy for Distal Ureteral Stones
}

\author{
Amr Fekry Elshorbagy, Karim Omar El Saeed, Mohammed Zaghlol Mohammed Mohammed * \\ Department of Urology, Faculty of Medicine, Ain Shams University \\ *Corresponding Author: Mohammed Zaghlol Mohammed Mohammed \\ Phone No.: (+2) 01066916213 \\ E-mail: mohamedzaghlolokla@gmail.com
}

\begin{abstract}
Background: urolithiasis is one of the most common diseases of the urinary tract. The lifetime prevalence of urinary stones is around $1 \%$ to $15 \%$ and the peak age of incidence is at 30 years. Men are affected 2 to 3 times more often than women. Ureteral stones account for $20 \%$ of the calculi in urolithiasis and about $70 \%$ of ureteral stones are present in the distal third of the ureter at the time of presentation. Aim of the work: this study aimed to compare the efficacy and safety of vardenafil (5mg twice daily) vs tamsulosin (0.4mg once daily) as a medical expulsive therapy in the management of distal ureteric stones (DUS) in terms of stone expulsion rate, stone expulsion time, number of pain episodes, analgesic use and side effects related to medical therapy. Patients and Methods: this was a prospective randomized comparative study conducted on 50 patients admitted through the outpatient Urology Clinic in Ain shams University Hospitals and Nasser Institute Hospital between February 2018 and August 2018. The patients were randomized using a closed envelope method. The patients were categorized into 2 main groups 25 patients each. Results: this study showed non significant stone expulsion rates and faster expulsion times in favor of vardenafil when compared to tamsulosin. Conclusion: both of the medications demonstrated a good safety and tolerability profile for medical expulsive therapy in patients with lower ureteric stones.
\end{abstract}

Keywords: vardenafil, tamsulosin, distal ureteral stones

\section{INTRODUCTION}

Urolithiasis is one of the most common diseases of the urinary tract. The lifetime prevalence of urinary stones is around $1 \%$ to $15 \%$ and the peak age of incidence is at 30 years. Men are affected 2 to 3 times more often than women. Ureteral stones account for $20 \%$ of the calculi in urolithiasis and about $70 \%$ of ureteral stones are present in the distal third of the ureter at the time of presentation ${ }^{(1)}$. Ureteral stones induce ureteral spasms that interfere with stone expulsion. Thus, reducing these spasms while maintaining normal peristaltic activity can facilitate stone expulsion. Almost 50\% of ureteral stones can pass spontaneously over time and stone size is the key factor for success. Stones smaller than $5 \mathrm{~mm}$ are expected to pass spontaneously, but only $20 \%$ of stones larger than $8 \mathrm{~mm}$ can pass (2). The management of ureteric stones had changed greatly over the last two decades, especially after the introduction of shockwave lithotripsy (SWL) and ureteroscopy, as minimally invasive treatments. However, these treatments are not risk free and are expensive ${ }^{(3)}$.
Multiple management options for ureteric stones are present, such as conservative, medical expulsive therapy (MET), extracorporeal shockwave lithotripsy (ESWL), ureteroscopy and open surgical procedures. MET includes various drugs, such as aadrenergic blockers, PDE5 inhibitors, calcium channel blockers and anti-inflammatory drugs, which have a relaxant effect on the ureteric smooth musculature ${ }^{(4)}$.

Stone clearance of distal ureteral stones (DUS) can be affected by several factors such as stone size, number, site and also the presence or absence of ureteric smooth muscle spasm and/or submucosal oedema ${ }^{(5)}$. The $\alpha$ receptors have the subtypes $\alpha 1$ and $\alpha 2$. $\alpha 1$ adrenoceptors were classified into three different subtypes of $\alpha-1 \mathrm{~A}, \alpha-1 \mathrm{~B}$ and $\alpha-1 \mathrm{D}$, of which the distribution in the ureter was $\alpha-1 \mathrm{D}>\alpha-1 \mathrm{~A}>\alpha$ $1 \mathrm{~B}$. The $\alpha 1 \mathrm{~A}-$ and $\alpha 1 \mathrm{D}$-adrenoceptors are the most abundant subtypes in the distal ureter. Stimulation of these $\alpha 1$-adrenoceptors leads to increases in both the frequency of ureteric peristalsis and the force of ureteric contractions. So, blockage of these receptors decreases basal ureteric tone, decreases 
peristaltic amplitude and frequency, leading to a decrease in intra-luminal pressure which increases the rate of urine transport and thus increasing the chance of stone passage ${ }^{(6)}$. Tamsulosin is a selective $\alpha 1$-blocker with a 10 -fold greater affinity for the $\alpha 1 \mathrm{~A}$ and $\alpha 1 \mathrm{D}$ adrenoceptor subtypes than for the $\alpha 1 \mathrm{~B}$ adrenoceptor subtype ${ }^{(7)}$. Tamsulosin is safe and well tolerated, side-effects may occur such as retrograde ejaculation, which is reversible, and orthostatic hypotension. Cardiovascular adverse effects may occur so a Highly selective $\alpha 1 \mathrm{~A}$ adrenoceptor blockers have been developed to minimize the cardiovascular adverse effects with increasing their efficacy on the urinary tract ${ }^{(8)}$.Relaxation of the smooth muscles of the lower ureter plays a major role in MET. Cyclic adenosine monophosphate (cAMP) and cyclic guanosine monophosphate (cGMP) are important intracellular second messengers mediating cellular responses. An increase in cAMP and cGMP triggers a signal transduction cascade, which leads to smooth muscle relaxation. Cyclic nucleotides (cAMP and cGMP) are degraded by the enzyme phosphodiesterase 5 (PDE5). Thus, using PDE5 inhibitors can play a role in the relaxation of the smooth muscle of the ureter by preservation of cAMP and cGMP ${ }^{(4)}$.Vardenafil, a PDE5 inhibitor, acts by a nitric oxide/cGMP signaling pathway of smooth muscles, resulting in high levels of cGMP and thus causing relaxation of ureteral muscle ${ }^{(9)}$.

\section{PATIENTS and METHODS}

This was a prospective randomized comparative study conducted on 50 patients admitted through the outpatient Urology clinic in Ain shams University Hospitals and Nasser Institute Hospital between February 2018 and August 2018, the patients were randomized using a closed envelope method. The patients were categorized into 2 main groups 25 patients each.

- Inclusion criteria:

1) Sex: male or female

2) Age:18-55 years

3) Stone Criteria: a single radio-opaque unilateral distal ureteral stone located between the lower border of the sacroiliac joint and the vesico-ureteric junction ..... detected by US, plain X-ray and nonenhanced CT.
4) The stone size ranges between 5 and 10 $\mathrm{mm}$

5) Normal kidney function

- Exclusion criteria:

1) Age: less than 18 years or more than 55 years

2) Stone in the upper or middle ureteric segment

3) Stone size: less than $5 \mathrm{~mm}$ or more than 10 $\mathrm{mm}$

4) Multiple stones, bilateral ureteric stones.

5) Severe hydronephrosis, fever.

6) Impaired renal function.

7) Those with previous ureteric endoscopy or surgery.

8) DM, peptic ulcer.

9) UTI.

10) pregnant or lactating women

11) Congenital or anatomical urinary tract malformations

12) Impacted stones more than 2 weeks

\section{- Methods:}

All patients who presented with a single, unilateral, uncomplicated distal ureteral stones (DUS) of 5-10 mm diagnosed by plain abdominal radiograph of the kidneys, ureters and bladder (KUB), ultrasonography and nonenhanced spiral CT. Detailed history intake: personal history, complaint, present history (Pain: site, radiation, intensity, onset, course), past history, family history of stone disease, history of medical disease such as diabetes, hypertension, cardiac etc., history of drug intake, surgical history.Full lab investigations as blood urea and creatinine levels, complete blood counts and urine analysis of all patients were obtained on admission. Every patient was provided informed written consent after receiving information about the nature of the study, time to study end, adverse effects and the possibility of intervention if needed.

\section{These patients were randomly categorized into 2 groups:}

- Group A:25 patients were received vardenafil $5 \mathrm{mg}$ tab/12 hours for 28 days

○ Group B:25 patients were received tamsulosin $0.4 \mathrm{mg}$ cap/day for 28 days

All patients were prescribed $50 \mathrm{mg}$ diclofenac on demand for pain relief with a maximum dose of $150 \mathrm{mg}$ per day. The patients were advised that on experiencing an episode of intractable ureteric colic, fever or 
severe hematuria they should immediately come to the hospital. Follow-up performed every week by asking the patient about stone passage, attacks of renal colic, time of stone passage, and symptoms related to side-effects of the drugs (Retrograde ejaculation, orthostatic hypotension and headache).Radiological assessment would be done every week with plain KUB. The patients followed-up until stone passage confirmed by plain KUB, non-contrast spiral CT or at the end of the study period (4 weeks).Success is defined as stone passage during the 28 days treatment period. Otherwise failure was an indication for ureteroscopy or ESWL.

\section{RESULTS}

Table 1: this table shows that there is no significant statistical difference among the studied groups regarding stone site, stone size $(\mathrm{p}>0.05)$

\begin{tabular}{|c|c|c|c|c|c|c|}
\hline \multirow{2}{*}{\multicolumn{2}{|c|}{ Variable }} & \multirow{2}{*}{\begin{tabular}{|l|} 
Vardenafil group \\
No. $=25$ \\
\end{tabular}} & \multirow{2}{*}{\begin{tabular}{|l|} 
Tamsulin group \\
No. $=25$ \\
\end{tabular}} & \multirow{2}{*}{ Test value } & \multirow{2}{*}{ P-value } & \multirow{2}{*}{ Sig. } \\
\hline & & & & & & \\
\hline Stone Size $(\mathrm{mm})$ & $\begin{array}{l}\text { Mean } \pm \text { SD } \\
\text { Range }\end{array}$ & $\begin{array}{l}7.40 \pm 1.71 \\
5-10\end{array}$ & $\begin{array}{l}7.24 \pm 1.81 \\
5-10\end{array}$ & $0.322 \bullet$ & 0.749 & NS \\
\hline Stone Site & \begin{tabular}{|l} 
Right \\
Left
\end{tabular} & $\begin{array}{l}13(52.0 \%) \\
12(48.0 \%)\end{array}$ & $\begin{array}{l}9(36.0 \%) \\
16(64.0 \%)\end{array}$ & $1.299^{*}$ & 0.254 & NS \\
\hline
\end{tabular}

*:Chi-square test; $\bullet:$ Independent t-test

Table 2: this table shows that there is no significant difference among the studied groups regarding number of renal colic episodes $(\mathrm{P}>0.05)$

\begin{tabular}{|c|c|c|c|c|c|c|}
\hline \multirow{2}{*}{\multicolumn{2}{|c|}{ Variable }} & \multirow{2}{*}{\begin{tabular}{|l|} 
Vardenafil Group \\
No. $=25$ \\
\end{tabular}} & \multirow{2}{*}{\begin{tabular}{|l|} 
Tamsulin group \\
No. $=25$ \\
\end{tabular}} & \multirow{2}{*}{ Test value } & \multirow{2}{*}{ P-value } & \multirow[b]{2}{*}{ Sig. } \\
\hline & & & & & & \\
\hline $\begin{array}{l}\text { NO. of } \\
\text { Renal colic }\end{array}$ & $\begin{array}{l}\text { Mean } \pm \text { SD } \\
\text { Range }\end{array}$ & $\begin{array}{l}1.91 \pm 0.92 \\
1-4\end{array}$ & $\begin{array}{l}2.05 \pm 0.90 \\
1-3\end{array}$ & $-0.497 \bullet$ & 0.622 & NS \\
\hline
\end{tabular}

$\because$ Independent t-test

Table 3: this table shows that there is no significant difference among the studied groups regarding analgesic use $(\mathrm{P}>0.05)$

\begin{tabular}{|l|l|l|l|l|l|l|}
\hline \multicolumn{2}{|l|}{\begin{tabular}{l} 
Variable \\
\cline { 3 - 7 }
\end{tabular}} & $\begin{array}{l}\text { Vardenafil group } \\
\text { No.=25 }\end{array}$ & Tamsulin group & $\begin{array}{l}\text { Test } \\
\text { value }\end{array}$ & P-value & Sig. \\
\hline $\begin{array}{l}\text { Analgesic Use } \\
\text { (Diclofenac } \\
\text { in mg) }\end{array}$ & $\begin{array}{c}\text { Median } \\
\text { (IQR) } \\
\text { Range }\end{array}$ & $\begin{array}{l}200(100-300) \\
50-500\end{array}$ & $\begin{array}{l}300(100-400) \\
50-450\end{array}$ & $-1.433 \neq$ & 0.152 & NS \\
\hline
\end{tabular}

f: Mann- Whitney test

Table 4: this table shows that the rate of stone expulsion rate is not significantly higher in the vardenafil group than tamsulosin group $(\mathrm{P}>0.05)$

\begin{tabular}{|c|c|c|c|c|c|c|}
\hline \multirow{2}{*}{\multicolumn{2}{|c|}{ Variable }} & \multirow{2}{*}{\begin{tabular}{|l|} 
Vardenafil group \\
No. $=25$ \\
\end{tabular}} & \multirow{2}{*}{\begin{tabular}{|l|} 
Tamsulin group \\
No. $=25$
\end{tabular}} & \multirow{2}{*}{ Test value } & \multirow{2}{*}{ P-value } & \multirow{2}{*}{ Sig. } \\
\hline & & & & & & \\
\hline $\begin{array}{l}\text { Stone } \\
\text { Expulsion Rate }\end{array}$ & $\begin{array}{l}\text { No } \\
\text { Yes }\end{array}$ & $\begin{array}{l}6(24.0 \%) \\
19(76.0 \%)\end{array}$ & $\begin{array}{l}7(28.0 \%) \\
18(72.0 \%)\end{array}$ & $0.104 *$ & 0.747 & NS \\
\hline
\end{tabular}

*: Chi-square test

Table 5: shows the mean of stone expulsion time is not significantly shorter in the vardenafil group than tamsulosin group $(\mathrm{P}>0.05)$

\begin{tabular}{|l|l|l|l|l|l|l|}
\hline \multirow{2}{*}{ Variable } & Vardenafil group & Tamsulin group & \multirow{2}{*}{ Test value } & P-value & Sig. \\
\cline { 2 - 7 } Stone Expulsion Time & No.=25 & No.=25 & & & \\
\hline \multirow{2}{*}{ Rean \pm SD } & $\begin{array}{l}9.95 \pm 5.12 \\
4-22\end{array}$ & $\begin{array}{l}11.28 \pm 5.98 \\
3-23\end{array}$ & $-0.729 \bullet$ & 0.471 & NS \\
\hline
\end{tabular}

$\because$ Independent t-test 
Table 7: this table shows that there is no significant difference among the studied groups regarding orthostatic hypotension, dizziness and headache $(\mathrm{P}>0.05)$. But there was significant difference among the studied groups regarding retrograde ejaculation $(\mathrm{P}<0.05)$

\begin{tabular}{|c|c|c|c|c|c|c|c|c|}
\hline \multirow{2}{*}{\multicolumn{2}{|c|}{ Variable }} & \multicolumn{2}{|c|}{ Vardenafil group } & \multicolumn{2}{|c|}{ Tamsulin group } & \multirow{3}{*}{$\begin{array}{l}\text { Test value* } \\
2.000\end{array}$} & \multirow{3}{*}{\begin{tabular}{|l} 
P-value \\
0.157
\end{tabular}} & \multirow{3}{*}{\begin{tabular}{|l} 
Sig. \\
NS
\end{tabular}} \\
\hline & & \multirow{2}{*}{\begin{tabular}{|l|} 
No. \\
18 \\
7 \\
\end{tabular}} & \multirow{2}{*}{$\begin{array}{l}\% \\
72.0 \% \\
28.0 \%\end{array}$} & \multirow{2}{*}{\begin{tabular}{|l|} 
No. \\
22 \\
3
\end{tabular}} & \multirow{2}{*}{$\begin{array}{l}\% \\
88.0 \% \\
12.0 \%\end{array}$} & & & \\
\hline Headache & $\begin{array}{l}\text { No } \\
\text { Yes }\end{array}$ & & & & & & & \\
\hline Dizziness & $\begin{array}{l}\text { No } \\
\text { Yes }\end{array}$ & $\begin{array}{l}17 \\
8\end{array}$ & $\begin{array}{l}68.0 \% \\
32.0 \%\end{array}$ & $\begin{array}{l}20 \\
5\end{array}$ & $\begin{array}{l}80.0 \% \\
20.0 \%\end{array}$ & 0.936 & 0.333 & NS \\
\hline Orthostatic Hypotenion & \begin{tabular}{|l} 
No \\
Yes
\end{tabular} & $\begin{array}{l}21 \\
4\end{array}$ & $\begin{array}{l}84.0 \% \\
16.0 \%\end{array}$ & $\begin{array}{l}23 \\
2\end{array}$ & $\begin{array}{l}92.0 \% \\
8.0 \%\end{array}$ & 0.758 & 0.384 & NS \\
\hline Retrograde Ejaculation & $\begin{array}{l}\text { No } \\
\text { Yes }\end{array}$ & $\begin{array}{l}21 \\
0\end{array}$ & $\begin{array}{l}100.0 \% \\
0.0 \%\end{array}$ & $\begin{array}{l}13 \\
6\end{array}$ & $\begin{array}{l}68.4 \% \\
31.6 \%\end{array}$ & 7.802 & 0.005 & HS \\
\hline
\end{tabular}

*: Chi-square test

\section{DISCUSSION}

Urolithiasis is a chronic disease with huge economic consequences and great public health importance, because it affects young people and has a high recurrence rate of approximately $50 \%$ within 5 years and $75 \%$ at 10 years. Although ureteric stones make up only $20 \%$ of urolithiasis, they are the most symptomatic of the calculi ${ }^{(10)}$. The use of medical therapy (such as a-Blockers, calcium channels blockers and corticosteroids) is justifiable to reduce edema, reduce spasm, and relax the smooth muscles for stone expulsion. MET has recently emerged as an alternative strategy for the initial management of selected patients with distal ureteral stones ${ }^{(11)}$.aBlockers are the most frequently used MET by urologists and different types are used based on thesubtype of a-receptor. Tamsulosin, alfuzosin, terazosin and silodosin are the most frequently used a-blockers in the literature. Highly selective a1A-adrenoceptor blockers have been developed to minimise the cardiovascular adverse effects while maintaining their efficacy on the urinary tract ${ }^{(12)}$.We decided to use vardinafil also on the basis of reports of Gratzke et al. ${ }^{(11)}$ who demonstrated the role of phosphodiesterase inhibitors in relaxation of ureteric muscles in the rank order of vardenafil $>$ sildenafil $>$ tadalafil.A limitation of the present study is the absence of assessment of the impact of vardinafil on the frequency of sexual intercourse of the study population. Therefore, we cannot define the exact mechanism of action of vardinafil, whether it is due to an increase in sexual intercourse or due to direct effects on the musculature of the distal part of the ureter. Moreover, the type of neural stimulus that is delivered to the distal ureter during sexual intercourse still needs to be clearly defined. In this study we found that the stone expulsion rate was non significantly higher in vardenafil group compared with tamsulosin group. The stone expulsion rate was $76.0 \%$ and $72.0 \%$ respectively, and we find that the mean of stone expulsion time was not significantly shorter in vardenafil group (9.95 days) than tamsulosin group (11.28 days).Puvvada $\boldsymbol{e t} \boldsymbol{a l}$. reported that the stone expulsion rates for tadalafil and tamsulosin were $84.0 \%$ and $68.0 \%$ respectively $(\mathrm{P}$ value $=$ 0.0130 ), and shorter stone expulsion time in patients who were given tadalafil $(14.7 \pm 3.8)$ in comparison to patients who were given tamsulosin $(16.8 \pm 4.5)$ was observed ${ }^{(13)}$. Hari et al. reported that the stone expulsion rates for tadalafil and tamsulosinwere $84.1 \%$ and $61.0 \%$ respectively $(\mathrm{P}$ value $=0.017)$. The mean stone expulsion time was lower in patients who were given tadalafil (8.08 \pm 3.3 days) than in patients who were given tamsulosin $(9.64 \pm 3.8$ days), but this difference was not significant $(p=0.094){ }^{(14)}$. Shokeir et al. reported that the stone expulsion rates for sildenafil citrate and placebo group were $67.3 \%$ and $40.4 \%$ respectively. The mean time to stone expulsion was shorter in the sildenafil citrate group $(\mathrm{P}<0.001)$. The mean time to stone expulsion was shorter in the sildenafil citrate group (11.5 days) compared with the placebo group (17.2 days).This difference was not significant $(\mathrm{P}<0.001)^{(4)}$. In this study we found that both drugs were safe with few side effects, one of these complications is headache which is one of alpha blockers and PDE5 inhibitors complications and in this study, it was recorded $28 \%$ of vardenafil group and $12 \%$ of 
tamsulosin group. Puvvada et al ${ }^{(13)}$ reported that the headache was $14 \%$ of patients for tadalafil and $11 \%$ of patients for tamsulosin. Hari et al. ${ }^{(14)}$ reported that the headache was $27.3 \%$ of patients for tadalafil and $14.6 \%$ of patients for tamsulosin. Shokeir et al. (4) reported that the headache was $4 \%$ of patients for sildenafil citrate and $0 \%$ of patients for placebo.Also in this study, dizziness was recorded $32 \%$ for vardenafil group and 20\% for tamsulosin group. Puvvada et al. (13) reported that dizziness was $12 \%$ of patients for tadalafil and $10 \%$ of patients for tamsulosin. Hari et al. ${ }^{(14)}$ reported in 2016 that the headache was $18.2 \%$ of patients for tadalafil and $12.2 \%$ of patients for tamsulosin. Another complication in our study was orthostatic hypotention that there was reported in 4 patients $(16 \%)$ in vardenafil group and 2 patients (8\%) in tamsulosin group. Puvvada et al. reported in 2016 that dizziness was $8 \%$ of patients for tadalafil and $10 \%$ of patients for tamsulosin. Hari et al. ${ }^{(14)}$ reported that the headache was $15.9 \%$ of patients for tadalafil and $9.8 \%$ of patients for tamsulosin. Finally, retrograde ejaculation which was also another complication in our study was reported in $31.6 \%(6 / 19)$ of male patients for tamsulosin group. Retrograde ejaculation was not reported in male patients for vardenafil group. Puvvada et al. reported in 2016 that a significantly higher incidence of abnormal ejaculation in the tamsulosin group in comparison to the tadalafil group (12 and $6 \%$ respectively) ( $<<0.002)$. The European Association of Urology (EAU) Nephrolithiasis Guidelines Panel (March 2018) has published guidelines for the management of ureteric calculi that medical expulsive therapy, using $\alpha$-blockers, seems to be efficacious treating patients with ureteric stones that are amenable to conservative management. Patients benefitting most might be those with larger (distal) stones. And that there is no or insufficient evidence to support the use of phosphodiesterase type 5 inhibitor (PDE-5i) or corticosteroids in combination with $\alpha$-blockers as a standard adjunct to active stone removal.

Additional studies with more patients are invited to consolidate the results of the present study. Further investigation into the types of neurotransmitters active in the distal ureter are needed, as knowing the exact types of these transmitters will open a new horizon for MET.

\section{CONCLUSION}

This study showed no significant higher stone expulsion rates and faster expulsion times in favor of vardenafil when compared to tamsulosin. Both of these medications demonstrated a good safety and tolerability profile for medical expulsive therapy in patients with lower ureteric stones.

\section{REFERENCES}

1. Pearle MS and Lotan Y (2012): Urinary lithiasis: etiology, epidemiology and pathogenesis. In: Campbell-Walsh Urology. Wein AJ, Kavoussi LR, Novick AC, Partin AW, Peters CA, editors. $10^{\text {th }}$ ed. Philadelphia: Saunders Elsevier, pp: 1257-1286.

2. Ueno A, Kawamura T, Ogawa A et al. (1977): Relation of spontaneous passage of ureteral calculi to size. Urology, 10: 544-550.

3. Pickard R, Starr $\mathrm{K}$ and MacLennan $\mathbf{G}$ (2015): Medical expulsive therapy in adults with ureteric colic: A multicentre, randomised, placebo-controlled trial. Lancet, 386: 341-349.

4. Shokeir AA, Mohamed AT, Ahmed EA et al. (2016): Sildenafil citrate as a medical expulsive therapy for distal ureteric stones: a randomized doubleblind placebo-controlled study. Arab Journal of Urology, 14: 1-6.

5. Sur RL, Shore $N$ and L'Esperance $J$ (2015): Silodosin to facilitate passage of ureteral stones: A multi-institutional, randomized, double-blinded, placebocontrolled trial. Eur. Urol., 67:959-964.

6. Itoh Y, Okada A and Yasui T (2013): Administration of the selective alpha 1Aadrenoceptor antagonist Silodosin facilitates expulsion of size $5-10 \mathrm{~mm}$ distal ureteral stones, as compared to control. Int. Urol. Nephrol., 45:675-678.

7. Griwan MS, Singh SK and Paul $H$ (2010): The efficacy of tamsulosin in lower ureteral calculi. Urol. Ann., 2: 6366.

8. Furyk JS, Chu K and Banks C (2015): Distal ureteric stones and tamsulosin: A 
double-blind, placebo-controlled, randomized, multicenter trial. Ann. Emerg. Med., 67: 86-95.

9. Gratzke C, Uckert S and Kedia G (2007): In vitro effects of PDE5 inhibitors sildenafil, vardenafil and tadalafil on isolated human ureteral smooth muscle:a basic research approach. Urol. Res., 35: 49-54.

10. Hollingsworth JM, Rogers MA, Kaufman SR et al. (2006): Medical therapy to facilitate urinary stone passage: A meta-analysis. Lancet, 368: 1171-1180.

11. Seitz C, Liatsikos E and Porpiglia F (2009): Medical therapy to facilitate the passage of stones: what is the evidence? Eur. Urol., (3):455-471.
12. Al-Ansari A, Al-Naimi A, Alobaidy AL et al. (2010): Efficacy of tamsulosin in the management of lower ureteral stones: a randomized double-blind placebocontrolled study of 100 patients. Urology, 75: 4-7.

13. Puvvada S, Mylarappa $P$, Aggarwal $K$ et al. (2016): Comparative efficacy of tadalafil versus tamsulosin as the medical expulsive therapy in lower ureteric stone: a prospective randomized trial. Cent. European J. Urol., 69: 178-182.

14. Hari BKC, Anil S, Ganesh B et al. (2016): Tamsulosin versus tadalafil as a medical expulsive therapy for distal ureteral stones: a prospective randomized study. Investig. Clin. Urol., 57: 351-356. 